\section{Research Article}

(c) 2021 Mostafa et.al..

This is an open access article licensed under the Creative Commons Attribution-NonCommercial 4.o International License

(https://creativecommons.org/licenses/by-nc/4.o/)

Received: 7 October 2020 / Accepted: 11 December 2020 / Published: 17 January 2021

\title{
The Mediating Effect of Person-Organization Value Fit on the Relationship Between University branding and Academic Staff Citizenship Behavior
}

\section{Bassant Adel Mostafa}

Lecturer, Faculty of Business Administration,

Economics and Political Science,

The British University in Egypt "BUE",

Suez Desert Road, El Sherouk City, Cairo 11837 Egypt

\section{Azza Abd-Elqader El-Borsaly}

Associate Professor, Faculty of Business, Ain Shams University,

El Khalefa El Mamoon Street, Cairo 11566, Egypt

\section{Eglal Abd-Elmoneim Hafez}

Professor, Faculty of Business, Ain Shams University, El Khalefa El Mamoon Street, Cairo 11566, Egypt

\section{Sally Ali Hassan}

Lecturer, Faculty of Business, Ain Shams University, El Khalefa El Mamoon Street, Cairo 11566, Egypt

DOI: https://doi.org/10.36941/ajis-2021-0027

\section{Abstract}

Nowadays, research on employer branding is still growing. A specific focus on branding in the higher education sector is still limited, so this research investigates how employer branding impacts organization citizenship behavior and whether person-organization value fit mediates this relationship on a sample of 332 academic staff members working in the private higher education sector in Egypt. The data collection was performed using a self-administered survey. The research employs correlation and regression analysis to test the research hypotheses. First, the results revealed a moderately significant effect of employer branding practices on organizational citizenship behavior. Second, person-organization value fit has a positive significant mediation effect on the relationship between employer branding and organizational citizenship behavior. These results will help private universities determine to what extent investing in building a strong employer brand will help retain academic staff members.

Keywords: University branding, Employer Branding, Organizational Citizenship Behavior, Person Organization Value Fit and Private Higher Education Sector 


\section{Introduction}

Nowadays, intensive competition among organizations across different industries has forced organizations to differentiate themselves from their competitors by providing the employees; who are considered one of the most significant assets for any organization (Burawat, 2013), with a certain "package of benefits" that seem attractive for their employees (Sharma, 2018). This, in turn, helps the organizations to earn the label of "great place to work" and "most attractive employer in the market" (Tanwar, 2017). In this context, in the current employment environment where "the war for talent" has intensified to attract and retain the most talented individuals, organizations apply brand management principles to human resources, which has led to the introduction of employer branding concept (Gozukara \& Hatipoglu, 2016) which is rapidly emerging as a strategic human resources tool to attract and retain a talented workforce, which in turn helps an organization deliver better service and achieve higher profits (Rampl \& Kenning, 2014). The employment brand highlights the firm's employment offerings' unique aspects to differentiate themselves and market the unique employment proposition they can offer (Ewing et al., 2002).

Moreover, to ensure the sustainability of any organization, it is currently considered insufficient for the employees to fulfill their tasks just in the context of the job description only (Ozçelika \& Afacan, 2014). Still, it is revealed that employees' behavior beyond specified role definitions leads to more positive results (Mohanty \& Rath, 2012), such as high performance, lower turnover, speed, and high accuracy in task completion, profitability, lower operating costs (Podsakoff et al., 2009). This behavior is known as extra-role activities, which have been termed later as Organizational Citizenship Behavior (OCB) (Ozçelika \& Afacan, 2014). Person-organization fit (P-O fit) is considered an essential dimension for enhancing citizenship behavior; it is the degree to which an employee perceives compatibility within the workplace. When employees perceive P-O fit, they try to make extra contributions to their companies by helping others, supporting co-workers, and participating in discretionary organizational activities (Wei, 2012).

The main reason for selecting the private higher education sector as an application area is a growth in the Egyptian private higher education sector. According to the reports issued by the Supreme Council of Universities (2019), the number of newly established private educational universities has been increasing throughout the past years, which creates a variety of choices offered to academic staff, and in turn, increases the competition between universities to hire new staff and maintain current ones. Besides, the lack of academics' awareness of employer branding attributes employed by their existing universities would affect academics who deliver brand values, represent the brand image, and are considered an essential source of attracting potential hires (Ivy, 2001).

Those academics' behavior is shaped by a continuous comparison that is done intrinsically between 'what employer brand attributes they expected from their universities' and 'what they actually experienced/received from those attributes in real working life'. According to Hoffman and Woehr (2006), expectations are shaped according to academics' values, ethics, personality, and aspirations. As a result, a significant fit between the individual and the organization would significantly decrease the gap between expectations and reality. By closing the gap between academics' expectations of employer branding attributes and the reality they actually experience through better person-organization fit, universities would expect to witness a significant increase in organizational citizenship, which would enhance their brand.

Therefore, an important question arises: How to stimulate organization citizenship behaviors among academic staff in private universities? The available literature investigating the relationship between the variables mentioned above is limited. Moreover, previous researchers have identified employer branding attributes from potential employees' perspectives; however, there is a difference between existing and potential employee perception regarding employer branding (Tumasjan et al., 2020). Accordingly, this study will be conducted based on the assumption that P-O fit, which is believed to be one of the precursors of OCB (Ruiz-Palomino \& Martinez-Canas; 2014; Gozukara \& Hatipoglu, 2016) would significantly enhance the relationship between EB and OCB when it acts as a mediator in 
this relationship. This relationship will be investigated in Egyptian private universities from the perspective of current academic staff.

\section{Literature Review}

\section{$2.1 \quad$ Employer Branding (EB)}

The theoretical foundation of employer branding is related to the assumption that employees are the most valuable assets in any organization, and employers who have expertise in human capital investment would benefit from higher performance (Burawat, 2013). Ambler and Barrow (1996) first introduced the term employer brand, who identified three fundamental values as psychological, functional, and economic values to define the employer brand and determine the unique attributes that differentiate them from competitors. These attributes must be accurate, realistic, and reflective of what the employer actually offers. Burawat (2013) further explained functional benefits as employee development and job roles, economic benefits as material or financial rewards, and psychological benefits such as satisfaction and recognition. Many authors have proposed different views by describing employer branding as a strategy to build an image in the minds of the potential employees to be "a great place to work" or become an employer of choice (Ewing et al., 2002).

Building on the work of Ambler and Barrow (1996); Schlager et al. (2011) expanded Employer branding practices to include five behavioral values such as development, social, reputation, diversity, and economic values that have been used in this research to measure Employer branding practices in private higher education institutions. Economic value is identified as having a "good salary," a "fair number of holidays," and "reasonable retirement benefits." While developmental value was referred to as having "good training opportunities," an "empowering environment," and a "good mentoring culture," as for social value, it encompassed a "strong team spirit," "competent co-workers," a "friendly relationship amongst individual co-workers" and a "respectful environment." Diversity value referred to interesting job characteristics, "challenging tasks" and a "wide variety of tasks" and finally reputation value, which was defined as employee's beliefs about how other people evaluate an employer, "good reputation of the company among friends," and "good brand to have on one's resume'.

Any organization should create an employer brand for several important reasons. First of all, the brand helps the company develop a positive image and improve its reputation in the labor market. Next, consistent and accurate information (promises) about employment offerings encourages employees to start and stay with a company and reduce turnover. Besides, various studies have researched that loyal employees to their employer brand increase customer satisfaction and an increase in financial indicators such as sales, profit, share value (Greshowak, 2015), higher organization performance, and enhanced recruitment efficiency (Tumasjan et al., 2020).

Furthermore, EB creates an accurate differentiation of the organization characteristics as an employer from those of its competitors; EB becomes especially relevant in today's business setting because high potential-employees are challenging to find (Bejtkovský \& Copca, 2020). Lastly, employer brands may encourage employees to engage in citizenship behavior and reflect a positive image of external stakeholders (Maxwell \& Knox, 2009).

\subsection{University Branding}

Nowadays, with the increasing number of private universities, this provides academic staff with a greater chance of mobility from one university to the other with nearly no switching costs, which means that the point of difference between private universities is low, leading to less retention and loyalty intentions so intense competition has increased the importance of branding in academia. For universities to improve the number and quality of students (Suomi 2014), they need to attract and recruit high talented employees and distinguish themselves from other competitors' in higher education (Guzmán et al., 2009). This should encourage universities to create a point of differentiation: 
to provide staff members with 'the best place to work for', which could be achieved through implementing an effective employer branding strategy.

Thus, employer branding would help organizations pinpoint and develop the most valuable practices that motivate staff members to maintain employment with their current employers (Bejtkovský \& Copca, 2020). Universities should focus on building attractive EB strategies to increase the university's appeal to talented academics with needed skills and knowledge. Universities can then keep those staff for a long time to win a sustainable, long-lasting competitive edge in the educational sector. Also, current academics' positive word of mouth will help the university attract potential candidates and retain existing talent (Kaur \& Syal, 2017). However, the role of employer branding as part of brand management strategy is not clearly understood in the higher education context, especially in its relation to positive organizational outcomes; since employer branding helps in attracting, motivating, and retaining high-talented employees (Bejtkovský \& Copca, 2020) therefore, this paper will contribute to knowledge in this area.

\subsection{Organizational Citizenship Behavior (OCB)}

It is observed that some individuals voluntarily help others in the workplace, promoting their employer's excellence without either an explicit or implicit promise of reward for such behavior; this conduct is known as organizational citizenship behavior (Asha \& Jyothi, 2013). Usually, such action is not specifically rewarded by organizations, yet individuals who demonstrate such behavior are often seen as having a favorable attitude towards overall business efficacy (Asha \& Jyothi, 2013). This kind of behavior is defined as the behavior performed to fulfill the functions more efficiently, voluntarily, and without considering the organization's formal reward system (Ozçelika \& Afacan, 2014).

The earliest dimensions of OCB were introduced by Smith et al. (1983), who identified two dimensions known as altruism and general compliance. Later in 1988, Organ maintained altruism and renamed general compliance as conscientiousness and added civic virtue, courtesy, and sportsmanship behavior to OCB dimensions. Podsakoff et al. (2009) pointed out that although many researchers use different evaluation dimensions, the most common measurement methods classify OCB into the following:

Altruism (helping behavior): is taking the initiative to help members of an organization resolve problems; it involves voluntarily helping others with an organizationally relevant task, problem, or heavy workload (Ariffin, 2014). Conscientiousness: is complying with organizational rules and going beyond minimum requirements through hard work, such as going beyond the required levels of attendance, punctuality, protecting resources, and related matters of internal maintenance (Ariffin, 2014). Sportsmanship: is obeying organizational regulations, tolerating imperfect situations without complaint, and consistently maintaining a positive attitude under unexpected circumstances through raising constructive ideas (Podsakoff et al., 2009). Courtesy (Good manners): are behaviors aimed at preventing work-related problems with others, such as not abusing the rights of others and treating others with respect (Ariffin, 2014). Civic virtue is referred to as remaining attentive and proactive when participating in organizational activities; it reflects responsive, constructive, or active involvement in the organization (Podsakoff et al., 2009). Therefore, OCB refers to individuals' informal responsibilities that can derive intrinsic motivation and positively impact overall organizational performance (Asha \& Jyothi, 2013).

\subsubsection{Organizational Citizenship Behavior and Employer Branding in Higher Education}

The backbone of any country has a good educational system that can make one country rise to the other (Noor, 2009). Universities are organizations that focus on knowledge formulation, transfer of information through teaching, and research activities. Since the educational quality and accreditation bodies are continuously developing new standards for evaluating universities' performance, these new quality standards might require changes in organizational culture, educational objectives, exam 
pattern, curriculum and quality, and quantity of research produced by academics (Eyupoglu, 2016). Universities are pushing their staff to fulfill those requirements to enhance their image and status in the market; they expect staff members to go beyond the minimum performance standards required to do their tasks and participate actively in achieving and maintaining the standards imposed by those quality control bodies (Eyupoglu, 2016). Consequently, to meet quality standards, universities should try to develop organizational citizenship behavior.

It is clear evidence that OCB's study in the academic field is of high value and certainly needs attention (Farooqui, 2012). According to Noor (2009), teachers are considered the core asset for any educational system; its success depends mainly on the capability, and quality of the teachers and particularly those with a high level of OCB have more value as compared to others because of the high quality of services they deliver to the students. Past studies have found that teachers' OCB significantly predicts high students' academic achievement (Khalid et al., 2009 and Eyupoglu, 2016). Different forms of citizenship behavior in the educational field would include: offering help to new instructors, delivering classes during staff member's day off with no extra fees, student tailored instructions, providing course material using innovative techniques, accepting new tasks with no additional monetary pay, helping students beyond office hours, offering extra help to needy students (Oplatka, 2006).

Mishra and Subudhi (2019) supported the argument that citizenship behavior is stimulated by different factors shaping employer branding, such as internal culture, recognition, fun, and attractive work environment. Furthermore, an organization that invests in its employees affects its attractiveness as an employer. Such investments might include participation in decision making, offering relatively competitive pay, extensive training, career planning, advancement, regular fair performance appraisal, and feedback (Karolidis, 2016). Perceived employer attractiveness might be the driving force for employees to engage in OCBs (Gözükara \& Hatipoğlu, 2016).

There are limited studies available to measure OCB in higher education, which provides a good opportunity for filling the gap in this area. Reviewing past studies has also shown that most of the studies have attempted to understand the linkages between OCBs and other constructs such as leadership styles, job satisfaction, organizational justice rather than understanding the link between EB and OCBs in the context of higher education (Rose, 2012). Besides, several studies have stressed the importance of applying OCBs measurements in different cultures and contexts, as it might influence how OCBs are observed (Khalid et al., 2009). More studies are needed to explain a real link between these two concepts in a relatively new culture and context: higher education in Egypt. Therefore, the following hypothesis was developed:

H1: There is a significant positive effect of Employer Branding on Organizational Citizenship Behavior in Egyptian private universities.

\subsection{Person Organization Fit (POF)}

Attracting employees who have a good fit with their organization's values is a crucial issue for employers nowadays to create a brand that accurately reflects its own culture and personality (Sutarjo, 2011). The P-O fit can be understood as a fit between an employee's beliefs, values, and culture, on the one hand, and the employer's image on the other hand (Tanwar \& Kumar, 2019). Understanding the outcomes of compatibility between employees and their employers has made P-O fit an area of interest for research during recent years, as it has important implications for organizations such as employees feeling more satisfied with their jobs, more commitment, reduced turnover intention, and willingness to engage in citizenship behavior acts (Özçelik \& Findıklı, 2014).

There are different ways to assess $\mathrm{P}-\mathrm{O}$ fit through; personality congruence, value congruence, and goal congruence; some researchers have drawn their attention to $\mathrm{P}-\mathrm{O}$ fit's value component. Schlager et al. (2011) argued that the most frequently used method to assess P-O fit is value congruence. The reasons for using value congruence are; values that are held by employees and their organizations are relatively stable and not changing over time (Van Vianen, 200o); besides that, organizational value 
congruence leads to more positive and favorable organizational outcomes, including satisfaction, commitment and favorable behavioral intentions (O'Reilly et al., 1991; Karakurum, 2005).

Furthermore, values make up organizational culture, which acts as a guide for employees' behavior, which plays a crucial role in shaping employees' attitudes and behavior. Organizational values provide a proper justification for the employees' accepted behavior and actions and what is not accepted (Karakurum, 2005). Finally, value compatibility is one of the critical variables that influence organizational attraction and increases employee willingness to keep employment with a specific organization (Cable \& Judge, 1996; Lauver \& Kristof-Brown, 2001; Cable \& DeRue, 2002; Teimouri et al., 2016).

Person-organization fit could be measured either by direct measurement of perceived fit or by indirect measurement of fit. The "indirect fit," or sometimes referred to as calculated fit or objective fit, is measured by comparing individual characteristics with that of the organization. The "direct fit" or sometimes referred to as perceived fit or subjective fit, is measured by asking individuals directly to what extent they believe they fit in their current organization; fit exists when the employee perceives that he/she is compatible with the organizational environment (Santos \& De Domenico, 2015).

Moreover, it can be observed that the direct measures of perceived fit have been used more often, followed by indirect fit. Lauver and Kristof-Brown (2001) argued that it is the perception of fit that best predicts individual outcomes. Santos and De Domenico (2015) indicated that 66.7 percent of the research papers had applied the direct fit measures only. They also revealed that objective fit impacts an individual's behavior only if that person perceives that the fit exists. Hence, it is crucial to measure employees' perception of the fit existence and then calculate the objective (indirect) type of fit if needed.

\subsubsection{Person Organization Value Fit and Employer Branding}

The question of 'why many applicants are attracted to a specific organization, selected by specific employers and decide to stay in a specific organization' has drawn many researchers' attention; the concept of $\mathrm{P}-\mathrm{O}$ fit has been suggested to answer this question. Many researchers concluded that the higher the $\mathrm{P}-\mathrm{O}$ fit level is, the higher the organizational attractiveness is to individuals working there (Teimouri et al., 2016). When employees think about EB, they first consider how they experience the brand in their routine work. This experience shapes employees ' perceptions and behavior and is affected by management style, HRM practices, and branding attributes (Asfar \& Badir, 2016). Ergun and Tatar (2018) added that the social environment, career development and the application of what is learned in work-life improve employees' perception of mutual fit between the organization and its employees. This perception of fit creates strongly identified employees with high retention levels.

Every interaction an employee has with his organization shapes his perception of EB, which accordingly affects employee level of perceived P-O fit if they only perceive EB as attractive and different from other competitors (Santos \& De Domenico, 2015). The match between EB attributes and individuals' personal needs and expectations makes it easier for employees to increase their level of perceived fit with organizational values along their employment period and increase their willingness to recommend their organization to other potential members as a great place to work for (Karakurum, 2005).

Park (2018) stated that organizations should understand the important attributes that employers should address and ensure that those attributes are delivered to their employees so that the likelihood of securing P-O fit is increased. Tanwar and Kumar (2019) found that positive work culture where employees find congruence between their work-related values and organizational culture can create a strong $\mathrm{P}-\mathrm{O}$ fit. These work values could take the form of better policies regarding teamwork among employees, work-life balance, opportunities for growth, and an attractive salary structure.

To conclude, employer branding is expected to contribute to the internalization of employees' organizational values; therefore, employer branding would play a role in employees' perception of person-organization fit. This argument would lead to the development of the following hypothesis:

H2: There is a significant positive effect of Employer Branding on Person organization value fit 


\subsubsection{Person Organization Value Fit and Organizational Citizenship Behavior}

It can be seen that there are some behaviors that managers expect from employees but cannot be technically required from them because those behaviors are not detailed in the job descriptions (LePine et al., 2002). Employees decide to exhibit such behaviors consciously when they feel that their considerations, goals, values, and opinions are compatible with organizational culture and values. An individual who perceives a strong sense of fit with his/her organization is more satisfied with the tasks he performs, more motivated, and intrinsically motivated to display citizenship behavior more often (Afsar \& Badir, 2016).

Accordingly, a high fit of an individual's personality values with organizational culture would yield a good citizen who regularly exhibits discretionary behaviors that benefit both colleagues and the organization as a whole, contributing to organizational success. These discretionary behaviors might include sharing personal property, helping co-workers with work-related problems offering the required information when needed, making creative suggestions to improve operations inside the organization while promoting a positive image of the organization to people outside it (Khaola \& Sebotsa, 2015). Some researchers supported the argument that PO fit is considered an important factor for improving the sense of ownership that will be reflected on OCBs (Ozcelik \& Findikli (2014); RuizPalomino and Martinez-Canas (2014). Hence, the following hypothesis was developed in light of the above arguments:

$\mathrm{H}_{3}$ : There is a significant positive effect of person-organization value fit on organization citizenship behavior.

Reviewing the literature showed that limited studies had investigated the relationship between employer branding, person-organization value fit, and organizational citizenship behavior. This study will argue that POF, which is believed to be one of the precursors of OCB (Ruiz-Palomino \& MartinezCanas, 2014; Gozukara \& Hatipoglu, 2016), would significantly enhance the relationship between EB and OCB when it acts as a mediator in this relationship. As a result, the following hypothesis was developed:

$H_{4}$ : The relationship between employer branding and organization citizenship behavior is mediated by person-organization value fit.

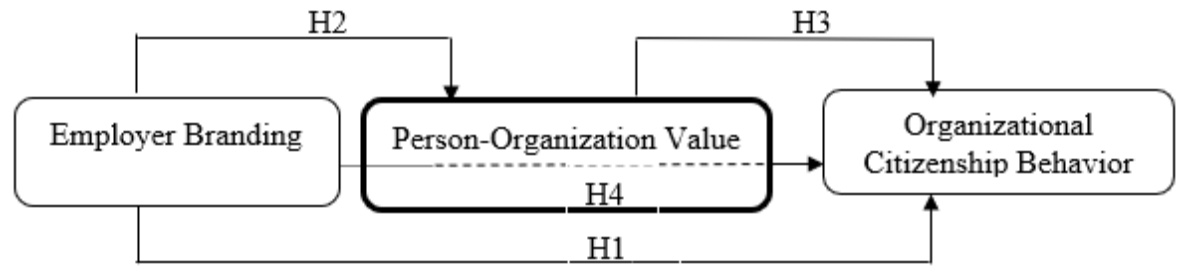

Figure 1: Research Model

\section{Research Method}

\subsection{Sampling}

Given the lack of sampling frame, non-probability quota sampling technique, in which a predetermined proportion of respondents are sampled from different private universities, including full-time academic staff members ranging from teaching assistants to professors from 7 selected private universities, the researcher could not cover all the population under study due to time limits and restrictions in accessing some universities. Out of the 400 surveys distributed, only 332 valid questionnaires were used in the analysis, with a response rate of $90.5 \%$. The respondents' mean age was 34 years, and $55 \%$ of them were females. The respondent's academic rank was distributed as follows: teaching assistant 
(40\%), lecturer assistant ( $20 \%)$, lecturer ( $17 \%)$, associate professor ( $16 \%)$, professor $(7 \%)$, and $55 \%$ of the respondents from faculties of science, while $45 \%$ were from faculties of humanity.

\subsection{Measures}

A five-point Likert-type scale was used, so strongly agree was represented by (5) to strongly disagree that was represented by (1) to measure EB, POF, and OCB. To measure employer branding as the independent variable in this study, staff members were required to evaluate their perception of employer branding attributes regarding their current university in terms of reputation, social, development, diversity, and economic values developed by Schlager et al. (2011). These measurement items were partly adapted from the study of Berthon et al. (2005) and modified by Schlager et al. (2011). The reliability of the scale used for each dimension was $0.82,0.84,0.82,0.71$, and 0.85 , respectively.

To measure the person-organization value fit (P-O-fit), two scales were used. The first scale was a three reflective item scale called "Direct Fit Scale," from Cable and Judge's (1996) study with the reliability of 0.92, which measures the overall value fit, along with a three-item measure of Lauver and Kristof-Brown's (2001) in which the reliability of the scale was 0.8 , these items together create an overall measure of the perceived level of POF.

The organization citizenship behavior (OCB) measure was adapted from Organ's (1988) items scale, including helping behavior Altruism, civic virtue, sportsmanship, courtesy and conscientiousness based on the recommendations of Podsakoff et al. (1990), with a reliability of 0.87 . These items were modified and combined to form an overall measure of organizational citizenship behavior as a dependent variable in this research.

Table (1): examples of an items used under each variable

\begin{tabular}{|c|c|}
\hline \\
\hline \multicolumn{2}{|c|}{ reputation value subscale is: ["...] Good employer name to have on my resume." } \\
\hline social value subscale is: & “[...] there is a friendly relationship among individual co-workers in this university.” \\
\hline development value subscale is: & "[...] there is a good internal training opportunity inside the university." \\
\hline economic value subscale is: & "[...] It provides a competitive salary package than others operating in the same field." \\
\hline diversity value subscale is: & "[...] there is a good variety of work activities inside the university". \\
\hline \multicolumn{2}{|c|}{ Person Organization Value Fit } \\
\hline PO - Value Fit & $\begin{array}{l}\text { "[...] I am able to maintain my values at this university." } \\
\text { "[...] I don't feel that I fit in this university because my values are different than } \\
\text { university values". }\end{array}$ \\
\hline \multicolumn{2}{|c|}{ Organization Citizenship Behavior } \\
\hline Altruism subscale is: & “[...] Even if I' am busy with my own work, I try to help others." \\
\hline Civic Virtue subscale is: & $\begin{array}{l}\text { "[...] I try to perform functions that are not required but strengthen the university image } \\
\text { without expecting any personal benefit." }\end{array}$ \\
\hline $\begin{array}{l}\text { Conscientiousness subscale } \\
\text { is: }\end{array}$ & $\begin{array}{l}\text { "[...]. I always apply university rules and regulations in everything I do, even when no } \\
\text { one is watching." }\end{array}$ \\
\hline Sportsmanship subscale is: & “[...] I don't complain about insignificant things at the workplace.” \\
\hline Courtesy subscale is: & "[...] I avoid taking actions without consulting others who might be affected." \\
\hline
\end{tabular}

\subsection{Statistical Analysis}

To measure the effect of the independent variable on the dependent variables, the Pearson correlation coefficient was first used to represent the strength and direction of the relationship between the research variables. A regression analysis was conducted to examine the extent to which the independent variable influences dependent variables in the presence of a mediating variable. 


\section{Results}

The employer branding (EB) was measured using 25 items, the reliability of the scale was measured, and the Cronbach's alpha was equal to .88. A Kaiser-Meyer-Olkin (KMO) measure of sample adequacy for the 25 items related to employer branding was found to be significant with a value of .843 . As for the organizational citizenship behavior scale (OCB), the survey consisted of 24 items; Cronbach's alpha was equal to .81. The person-organization value fit (POF) scale consisted of 7 items; Cronbach's alpha was equal to .91. The KMO test results were found to be significant with a value of .916. The high value indicated that the pattern of correlations among items is well above the recommended value of .5, as Field (2013) suggested.

Table (2): Pearson Correlation Test between EB, POF and OCB

\begin{tabular}{lcc}
\hline Research Variables & Pearson Correlation Coefficient & Significance (two-tailed) \\
\hline EB-POF & 0.567 & o.ooo \\
POF-OCB & 0.295 & o.ooo \\
EB-OCB & 0.323 & 0.0oo \\
\hline
\end{tabular}

* Correlation is significant at $\mathrm{p} \leq \mathrm{0.05}$ (two-tailed)

After conducting a correlation test, it was revealed that there is a significant positive, strong relationship between perceived EB and P-O value fit with a correlation coefficient value of approximately 0.6 , at a significant level less than 0.05 . Second, there is a significant positive moderate relationship between $\mathrm{P}-\mathrm{O}$ value Fit and $\mathrm{OCB}$, with a correlation coefficient value of approximately 0.3 , at a significance level less than 0.05. Finally, there is a significant positive moderate relationship between perceived EB and OCB, with a correlation coefficient value of approximately 0.3 , at a significance level less than 0.05 .

The following table summarizes the multiple regression analysis results that were conducted to test the research hypotheses.

Table (3): Multiple Regression Model for the effect of EB and POF on OCB

\begin{tabular}{lcc}
\hline Model & Unstandardized Coefficients $(\beta)$ & P-Value \\
\hline $\begin{array}{l}\text { Model 1 } \\
\text { (Direct effect) Regression of OCB on EB }\end{array}$ & 0.260 & 0.000 \\
$\begin{array}{l}\text { Model 2 } \\
\text { Regression of POF on EB }\end{array}$ & 0.914 & 0.000 \\
$\begin{array}{l}\text { Model 3 } \\
\text { Regression of POF on OCB }\end{array}$ & 0.150 & 0.000 \\
$\begin{array}{l}\text { Mediation Model 4 } \\
\text { (indirect effect) Regressing OCB on EB and POF }\end{array}$ & 0.187 & 0.000 \\
\hline
\end{tabular}

* Significant level at $\mathrm{p} \leq 0.05$ (two-tailed)

In model 1, EB was an independent variable, while OCB was the dependent variable. It showed that EB was positively correlated with OCB $\left(\beta_{1}=0.26, p<0.05\right)$, which means that when the perceived EB is enhanced by one unit, OCB increases by 0.26 units at a significant level less than 0.05 . Employer branding practices explained $10 \%\left(\mathrm{R}^{2}\right)$ of the variance in OCB.

Consequently, Hypothesis 1 was supported. In model 2, EB was used as an independent variable and POF as the dependent variable. It revealed that EB was positively associated with POF $\left(\beta_{2}=0.914\right.$, $\mathrm{p}<0.05)$. Employer branding practices explained $32 \%\left(\mathrm{R}^{2}\right)$ of the variance in POF. This supports Hypothesis 2. Moreover, in model 3, POF, a mediating variable, had a significant positive effect on OCB $\left(\beta_{3}=.15, \mathrm{p}<0.05\right)$. In this case, the $\mathrm{H}_{3}$ hypothesis was supported. As illustrated in Table (3), the mediation model (4) accounted for the direct effect between EB and OCB and also the indirect effect 
through POF. It is notable that after the inclusion of POF, the effect of EB on OCB decreased from $\beta 1$ $=0.26$ to $\beta_{4}=0.187$. The indirect effect on OCB was statistically significant $(p<0.05)$. The results of the mediation model suggest a partial mediation effect of POF on the relationship between EB and OCB. However, the direct effect of EB on OCB still exists. Thus, Hypothesis 4 was not completely supported.

\section{Discussion}

The main challenges that universities have to face are international competition and national competition, which forces universities to focus more than ever on building the right employer brand image internally and externally. University's staff members are the university image's main representatives to the public and the main contributor to high-performance universities. Therefore, a successful employer brand builds distinctiveness by searching for core strengths, and uniqueness of employment experience offered to and valued by employees and positioning this in their minds; distinctiveness in the labor market could be a leading strategy for organizational survival and success in winning the war for talent and eventually stand out from the crowd by differentiating itself as a desirable employer in the labor market (Yildiz, 2016).

Ultimately, one could interpret the combination of the previous analyses (correlation and regression analysis) that perceived employer branding practices do not strongly encourage citizenship behavior among employees; this weak influence could be explained for several reasons. First, there might exist a gap between the perceived employer brand and the actual experiences of the brand attributes within private universities. Academics might feel that the promises of the employer brand were not met, and thus it does not impact their OCB (Love \& Sing, 2011). To overcome this gap, universities should focus on delivering the promises declared in their branding messages to their employees. They should offer career development opportunities, enhance university reputation internally and externally, provide competitive financial packages to their staff, and support a creative and innovative environment, to build a strong employer brand.

Moreover, there were statistical indications that perceived employer brand's effect on organizational citizenship behavior is mediated by employees' perception of their fit with the organization's values. One explanation for POF's mediating effect in the relationship between EB and OCB suggests that the ongoing academic staff experience with their universities shapes their perception of the university brand attributes that affect their level of perceived culture fit throughout their employment period. This means that staff members who perceive their employer brand as an attractive brand will show a high level of perceived fit (EB-POF). This explanation is supported by arguments about the relationship between the employer brand and person-organization value fit (Santos \& De Domenico, 2015; Teimouri et al., 2016). Findings from the following studies (KristofBrown et al. 2005; Hoffman \& Woehr, 2006; Ruiz-Palomino \& Martínez, 2014) support the link between POF and OCB, which is based on the assumption that those who perceive a strong sense of fit between their values and university values, will be intrinsically motivated and tend to regularly engage in citizenship behavior acts that benefit both their coworkers and reflected on the university success at the end (OCB- POF).

\section{Conclusion}

This study empirically tested the extent to which an employer brand practices have an impact on organizational citizenship behavior among academic staff working in private universities in Egypt. For this purpose, the two constructs were examined. Moreover, this research aimed at measuring whether the congruence between academic staff perceived values with university values provided a mediating effect in the relationship between EB and academic citizenship behavior toward their universities. The results indicated a moderate effect of employer branding practices on academic staff citizenship behavior. Consequently, universities should be aware that academics who perceive their employer brand as attractive are not enough to develop and/or sustain strong organizational citizenship 
behaviors. Universities should continuously focus on filling the gap between the perceived employer brand, and the actual brand lived daily by their academics.

The results also suggest that when academic staff perceives a strong fit between their values and university values, this will strengthen the effect of perceived employer branding on their willingness to exhibit more citizenship behaviors toward fulfilling the university's goals by supporting and helping each other, increasing their desire to participate in discretionary organizational activities. Consequently, private universities should direct their efforts toward finding different ways to strengthen person-organization value fit among staff members by developing a favorable organizational culture with values that are congruent with their academic staff. The greater the POF, the more significant is the effect of employer brand on OCB.

\subsection{Theoretical and practical contributions}

The study aimed to contribute to the research field by including employer branding, personorganization value fit, and organizational citizenship behavior all together in one model in the private higher education sector in the Egyptian context. From this perspective, the results of this research suggest that the higher the academic staff perception of strong fit between their values and those of the university they work for, the more ready they are to exert more efforts or to engage in extra-role behavior; accordingly, person-organization value fit has a significant positive partial mediation effect on the relationship between EB and citizenship behavior. This result reflects the importance of having a high level of fit between university values and academic staff values. Few studies have focused on the link between how academic staff perceives their university brand image and their effort to do extra work for the organization.

One way to enhance person-organization value fit is to select academic staff whose work-related values match those of their university values and culture, which could be done during the recruitment and selection phase by using situational/judgment reasoning tests that evaluate how applicants approach certain situations encountered in the workplace. The results from these tests will reveal value compatibility. Another way to achieve fit would be to develop an "Employee Advocacy day" or "meet our staff day," which means that during the orientation program, universities specify one day for new hires to meet current staff and share their experience with them, about what they do, what they are good at, how they are treated, how it is like working in this university, this is a way to describe the culture of the university to new hires, let current staff talk about their employer; this will increase the credibility of employer branding messages.

Person organization value fit could also be strengthened through "promoting a people-oriented culture" by ensuring transparency of information and having an open channel for multi-directional communication. For example, academic staff should be part of decision-making or at least to be consulted on significant university decisions that affect their learning, teaching, research process, or even working environment; this will help staff members feel connected and part of the larger team. Universities should attempt to institute university values in existing employees through regular training sessions. For example, if universities value teamwork, developing training sessions in a teambuilding atmosphere or assigning tasks involving the whole team members, not a specific individual, will help employees adjust their values with organizational values.

Besides, the results of this research will provide the selected universities with insight on determining to what extent investing in building a strong employer brand and in developing ways of enhancing person-organization fit will not only help the universities from the standpoint of attracting potential staff but will also help in encouraging academics to engage more in citizenship behavior act. Universities should focus on determining the aspects or organizational practices that academics find attractive or non-attractive and then formulate an EB strategy based on these practices, which would significantly impact citizenship behaviors. 


\subsection{Limitations and future research}

Some limitations of the study should also be noted. This paper was limited to academic staff working in private universities operating in Egypt; this applied study's results cannot be generalized to public universities or other sectors due to differences in terms of their objectives and practices. Person organization fit has many perspectives, and this research was limited to using one view of PO fit, which is the value congruence. It ignored other types like person job (P-J) fit, person vocation (P-V) fit, person-environment (P-E) fit, and person group (P-G) fit, which can be regarded as a limitation. Another limitation concerning the data collection technique is that it depends on the self-reporting method, potentially leading to common method bias.

Further focus and attention should be devoted in future studies to other moderating and mediating variables that could be added to the model, which could affect the relationship between EB, OCB such as organization identification, perceived organizational support, employee job engagement, and demographic variables. Moreover, the biased manner in which staff members evaluate their citizenship behavior intention, which calls for applying a different data collection tool such as qualitative method "interviews" to help provide rich information on how OCBs fit within the university environment or further research could use supervisors and peer rating aside with employee's rating to better predict the staff member's citizenship engagement level and avoid bias in answering OCB statements."

\section{References}

Ambler, T., \& Barrow, S. (1996). The employer brand. Journal of brand management, 4(3), 185-206. https://doi.org/10.1057/bm.1996.42

Afsar, B., \& Badir, Y. F. (2016). Person-organization fit, perceived organizational support, and organizational citizenship behavior: The role of job embeddedness. Journal of Human Resources in Hospitality $\mathcal{E}$ Tourism, 15(3),252-278. https://doi.org/10.108o/15332845.2016.1147936

Asha, C. S., \& Jyothi, P. (2013). Internal branding: A determining element of organizational citizenship behaviour. Journal of Contemporary Management Research, 7(1), 37 - 57.

Ariffin, H. F. (2014). Measuring organizational commitment through its relationship with organizational identity, organizational citizenship behaviour and organizational employer branding (Doctoral dissertation, Malaya university). Malaya University Archive.

Backhaus, K., \& Tikoo, S. (2004). Conceptualizing and researching employer branding. Career development international, 9(5), 501-517.

Bejtkovský, J., \& Copca, N. (2020). The Employer Branding Creation and HR Marketing in Selected Healthcare Service Providers. Management \& Marketing. Challenges for the Knowledge Society, 15(1), 95-108. https://doi.org/10.2478/mmcks-2020-00o6

Berthon, P., Ewing, M., \& Hah, L. L. (2005). Captivating company: dimensions of attractiveness in employer branding. International journal of advertising, 24(2), 151-172. https://doi.org/10.1080/02650487.2005.11072912

Burawat, P. (2013). The Relationships among Perceived Employer Branding, Employee Engagement, and Discretionary Effort in the Petroleum Industry (Doctoral dissertation, Rajamangala University of Technology Thanyaburi). Rajamangala University Archive. http://www.repository.rmutt.ac.th/xmlui/bitstream/handle/123456789 /1996/139301.pdf?sequence=1

Cable, D. M., \& DeRue, D. S. (2002). The convergent and discriminant validity of subjective fit perceptions. Journal of applied psychology, $87(5), 875-884$. https://doi.org/10.1037/oo21-9010.87.5.875

Cable, D. M., \& Judge, T. A. (1996). Person-organization fit, job choice decisions, and

organizational entry. Organizational behavior and human decision processes, 67(3), 294-311. https://doi.org/10.1006/obhd.1996.0081

Ergun, H. S., \& Tatar, B. (2018). Employer branding and employee attitudes: Mediating role of person-organization fit. Research Journal of Business and Management (RJBM), 5(2), 110-120. https://doi.org/10.17261/Pressacademia.2018.830

Ewing, M. T., Pitt, L. F., De Bussy, N. M., \& Berthon, P. (2002). Employment branding in the knowledge economy. International Journal of advertising, 21(1),3-22. https://doi.org/10.1080/02650487.2002.11104914 
Eyupoglu, S. Z. (2016). The organizational citizenship behaviour of academic staff in North Cyprus. Procedia Economics and Finance, 39,701-704. https://doi.org/10.1016/S2212-5671(16)30280-5

Farooqui, M. R. (2012). Measuring organizational citizenship behavior (OCB) as a consequence of organizational climate (OC). Asian Journal of Business Management, 4(3), 294-302.

Field, A. (2013). Discovering Statistics using IBM SPSS for Windows. London: SAGE.

Gözükara, İ., \& Hatipoğlu, Z. (2016). The effect of employer branding on employees' organizational citizenship behaviors. International Journal of Business Management E Economic Research, 7(1), 37-57. Available online at: https://pdfs.semanticscholar.org/7127/degdo982083e61af7b21a64eibd52od9802c.pdf?_ga=2.56052911.564615926.159 7177551-1280805496.1590441265

Greshowak, A. (2015). Employment branding and communication in an evolving mobile, technology and social mediabased society, (master's thesis, The College of St. Scholastica).

Guzmán, F., Abimbola, T., \& Whisman, R. (2009). Internal branding: A university's most valuable intangible asset. Journal of Product \& Brand Management. 18(5), 367-370. DOI: 10.1108/10610420910981846

Hoffman, B. J., \&Woehr, D. J. (2006). A quantitative review of the relationship between person-organization fit and behavioral outcomes. Journal of vocational behavior, 68(3), 389-399. https://doi.org/10.1016/j.jvb.2005.08.003

Ivy, J. (2001). Higher education institution image: A correspondence analysis approach. The International of Journal Education Management, 15(6), 276-282. https://doi.org/10.1108/09513540110401484

Karakurum, M. (2005). The effects of person-organization fit on employee job satisfaction, performance and organizational commitment in a Turkish public organization (master's thesis, Ankara: Middle East Technical University).

Karolidis, D. (2016). Organizational citizenship behavior the Greek public sector. (Master's thesis, University of Macedonia).

Kaur, J., \& Syal, G. (2017). Determinative impact of employer attractiveness dimensions of employer branding on employee satisfaction in the banking industry in India. Business Analyst, 37(2), 129-144.

Khalid, S. A., Ali, H., Ismail, M., Rahman, N. A., Kassim, K. M., \& Zain, R. S. (20o9). Organizational citizenship behavior factor structure among employees in hotel industry. International Journal of Psychological Studies, 1(1), 16. https://doi.org/10.5539/ijps.v1nıp16

Khaola, P. \& Sebotsa, T. (2015). Person-organisation fit, organisational commitment and organisational citizenship Behaviour. Journal of Management and Business Sciences, 67-74. http://dx.doi.org/10.6084/m9.figshare.1487700

Kristof-Brown, A. L., Zimmerman, R. D., \& Johnson, E.C. (2005). Consequences of individuals' fit at work: A metaanalysis of person-job, person-organization, person-group, and person- supervisor Fit. Personnel Psychology, 58(2), 281-342. https://doi.org/10.1111/j.1744-6570.2005.00672.x

Lauver, K. J., \& Kristof-Brown, A. (2001). Distinguishing between employees' perceptions of person-job and personorganization fit. Journal of vocational behavior, 59(3), 454-470. https://doi.org/10.10o6/jvbe.2001.1807

LePine, J. A., Erez, A., \& Johnson, D. E. (2002). The nature and dimensionality of organizational citizenship behavior: a critical review and meta-analysis. Journal of applied psychology, 87(1), 52-65. https://doi.org/10.1037/oo219010.87.1.52

Love, L. F., \& Singh, P. (2011). Workplace branding: Leveraging human resources management practices for competitive advantage through "Best Employer" surveys. Journal of Business and Psychology, $26(2), 175$. https://doi.org/10.1007/s10869-011-9226-5

Maxwell, R., \& Knox, S. (2009). Motivating employees to" live the brand": a comparative case study of employer brand attractiveness within the firm. Journal of marketing management, 25(9-10), 893-907. https://doi.org/10.1362/026725709X479282

Mishra, Y. and Subudhi, R. (2019). Technical and higher educational institutions of Odisha: A study on impact of employer branding and organization attractiveness on citizenship behavior. International Journal of Civil Engineering and Technology (IJCIET), 10(1), pp. 1965-1977.

Mohanty, J., \& Rath, B. P. (2012). Influence of organizational culture on organizational citizenship behavior: A threesector study. Global Journal of business research, 6(1), 65-76.

Noor, A. (2009, November). Examining organizational citizenship behavior as the outcome of organizational commitment: A study of universities teachers of Pakistan. Proceedings 2nd CBRC, Lahore, Pakistan.

Oplatka, I. (2006). Going beyond role expectations: Toward an understanding of the determinants and components of teacher organizational citizenship behavior. Educational Administration Quarterly, 42(3), 385-423. https://doi.org/10.1177/0013161X05285987

Organ, W. (1988). Organizational citizenship behavior: The good soldier syndrome. Lexington: Lexington Books.

O'Reilly III, C. A., Chatman, J., \& Caldwell, D. F. (1991). People and organizational culture: A profile comparison approach to assessing person-organization fit. Academy of Management Journal, 34(3), 487516. https://doi.org/10.2307/256404 
Özçelik, G., \& Fındıklı, M. A. (2014). The relationship between internal branding and organizational citizenship behaviour: The mediating role of person-organization fit. Procedia-Social and Behavioral Sciences, 15o(15), 1120-1128. https://doi.org/10.1016/j.sbspro.2014.09.127

Park, J. (2018). Higher education employees' self-assessment of person-organization fit: the role of work conditions and job satisfaction. International Review of Public Administration, 23(1), 55-77. https://doi.org/10.108o/12294659.2018.1447883

Podsakoff, N. P., Whiting, S. W., Podsakoff, P. M., \& Blume, B. D. (2009). Individual-and organizational-level consequences of organizational citizenship behaviors: A meta-analysis. Journal of applied Psychology, 94(1), 122-141. https://doi.org/10.1037/aoo13079

Rampl, L. V., \& Kenning, P. (2014). Employer brand trust and affect: linking brand personality to employer brand attractiveness. European journal of marketing.48(1/2), 218-236. DOI: https://doi.org/10.1108/EJM-02-2012-0113

Rose, K. J. (2012). Organizational citizenship behaviors in higher education: Examining the relationships between behaviors and performance outcomes for individuals and institutions (Doctoral dissertation. University of Arkansas). University of Arkansas Archive. https://scholarworks.uark.edu/etd/403/

Ruiz-Palomino, P., \& Martínez-Cañas, R. (2014). Ethical culture, ethical intent, and organizational citizenship behavior: The moderating and mediating role of person-organization fit. Journal of business ethics, 120(1), 95108. https://doi.org/10.1007/s10551-013-1650-1

Santos, L. B. and De Domenico, S.M.R. (2015). Person-organization fit: Bibliometric study and research agenda. European Business Review, 27(6), 573 - 592. http://dx.doi.org/10.1108/EBR-04-2015-0038

Sharma, R., Jain, V. \& Singh, S. (2018). The impact of employer branding on organizational commitment in indian IT sector. Journal of Business and Management, 20(1), 49-54. DOI: 10.9790/487X-2001054954

Schlager, T., Bodderas, M., Maas, P. \& Cachelin, J.L. (2011).The influence of the employer brand on employee attitudes relevant for service branding: an empirical investigation. Journal of Services Marketing, 25(7), 497508 https://doi.org/10.1108/o8876041111173624

Smith, C., Organ, D. \& Near, J. P. (1983). Organizational citizenship behavior: Its nature and antecedents. Journal of Applied Psychology, 68(4), 653-663. https://doi.org/10.1037/oo21-9010.68.4.653

Suomi, K. (2014). Exploring the dimensions of brand reputation in higher education: A case study of a Finnish master's degree programme. Journal of higher education policy and management, 36(6), 646-66o. https://doi.org/10.1080/1360o8oX.2014.957893

Supreme council of universities (2019, March 30). List of private universities in Egypt. Retrieved May, 2020, from http://scu.eg/pages/private_universities.

Sutarjo, A. (2011). Ten ways of managing person-organization fit (PO Fit) effectively: A literature study. International Journal of Business and Social Science, 2(21), 226-233.

Tanwar, K. (2017). The effect of employer brand dimensions on organizational commitment: Evidence from Indian IT industry. Asia-Pacific Journal of Management Research and Innovation, 12(3/4), $282-290$. https://doi.org/10.1177/2319510X17701854

Tanwar, K., \& Kumar, A. (2019). Employer brand, person-organisation fit and employer of choice. Personnel Review. 48(3), 799-823. https://doi.org/10.1108/PR-10-2017-0299

Teimouri, H., Jenab, K., Rafei, S., \& Yonespoor, M. (2016). Structural equation modeling to analyze personorganization fit and organizational effectiveness. International Journal of Electrical \& Computer Engineering, 6(6), 3006-3017. https://doi.org/10.11591/ijece.v6i6.116o8

Tumasjan, A., Kunze, F., Bruch, H., \& Welpe, I. M. (2020). Linking employer branding orientation and firm performance: Testing a dual mediation route of recruitment efficiency and positive affective climate. Human Resource Management, 59(1), 83-99. https://doi.org/10.1002/hrm.21980

Van Vianen, A.E. (200o). Person-organization fit: The match between newcomers' and recruiters' preferences for organizational cultures. Personnel Psychology, 53(1), 113-149. https://doi.org/10.1111/j.1744-6570.200o.tboo196.x

Yildiz, S. M. (2016). The effect of internal marketing on organizational citizenship behavior of academic staff in higher educational institutions. Universal Journal of Educational Research, 4(5), $1122-1128$. https://doi.org/10.13189/ujer.2016.040523 